\title{
Comparative Study of Mineral and Nutritional Composition of a Multifunctional Flora Composite Formulated from Seven Medicinal Plants and their Applications to Human Health
}

\author{
Paul SH*, Usman AA, Gana IN, Manase A, Adeniyi OD and Olutoye MA \\ Department of Chemical Engineering, Federal University of Technology Minna, Nigeria
}

Submission: February 26, 2018; Published: May 23, 2018

"Corresponding author: Paul Samson Habila, Department of Chemical Engineering, Federal University of Technology Minna, Nigeria, Email: paulkukah81@gmail.com

\begin{abstract}
A research titled "formulation and characterisation of a multifunctional flora composite for the prevention and management of diabetes" was carried out using seven medicinal plants. The product was examined for it nutritional content and the nutritional composition determined for each of the plants using proximate analysis. At the end of the research, the result shows that, on the average; Calcium (126.05) Potassium (382.40), Magnesium (74.35), phosphorus (120.90), Iron (mg/100g) (96.11), Zinc (12.94), Manganese (1.56), Sodium (96.21), Nickel (6.86) and Copper (1.10) respectively. Others per one hundred percent are; Carbohydrate (18.32), Crude proteins (10.98), Ash content (6.64), Moisture content (19.78), Fat (oil) content (5.53), Vitamins content (15.91), Fibre content (15.72) and Energy value (286.11) in kilocalories. Moringa has 440.00 milligrams per hundred grams of sample followed by turmeric with 228.8 milligrams per hundred grames of samples. The results shows that both plants contain essential nutritional and mineral composition required for human health as discussed.
\end{abstract}

Keywords: Nutrient; Minerals elements; Plants; Human health; Diabetes; High blood pressure .

\section{Introduction}

Right from the beginning of time since man came to being and given the responsibility of managing and exploring nature and its endowment, he has always made relentless efforts in order to provide for himself an affordable, comfortable, healthy and purposeful life. He does this by taking advantage of the knowledge, instinct and wisdom that the same nature has given to him over other animals [1]. One of the aspects of the man's life that has not only much value but also determines his productivity in all ramifications, is the aspect of his health. This is because human health is not just the engine for the functionality of the total man but also, determines his viability, sustainability, efficacy and productivity in all respects. Therefore, one cannot over emphasise the need for not just curing man of the effects of life's threatening illnesses that have confronted and are confronting him over the years and today, but also must as well, formulate methods and skills to stop, eliminate and or prevent these threats from occurring in the first place [2]. The major ways used by man to do this are: his feeding habit, life style, approach to problems and choice of environment to live in [1]. Since the day nature gave man, this opportunity to exist on this planet, it has been the daily quest of man to eat the best food, get the best things of life and perhaps live the best life. But the questions he has always asked and always had to answer by every means are: how would he achieve that? Who to achieve that for him? When to achieve that? Finally, where to get that done well? Although, he has made many attempts to achieve and attain this level of life, but, he has often failed but never relented [1] It is in this spirit of inquisitiveness that great achievements in the fields of health, engineering, technology, sciences, art and humanities have been made to mention but a few[1]. However, some of the errors made as a result of his quest to achieve greatness have also affected the ecosystem. Setting the natural forces against themselves and the worst of it is that most of this interactions between natural forces are also sometimes against mans healthy living. Consequently Because of the effects of industrial gases that chemically unbalanced the atmosphere, other related chemical emissions and or Global warming has in-turn, unbalanced man's body chemistry causing uncontrollable mutations and abnormal changes [3].

The Influence of these industrial uproars, environmental degradability and climate change, have left man with no choice than to adjust his life style to best fit the situations and circumstances that surrounds his life on a daily basis. Circumstances that have exposed him to not just dangerous, 
harsh and brutal environment conditions but also to life threatening and gravening diseases. Medicinal plants have become the most if not the only important sources of life-saving drugs for the larger percentage of the world's population. Consequences upon the time we are living in medicinal plants, their combinations derived from the wild indeed remains and will forever be of greater used to not only human beings but also to all living creatures on earth because, they do not only provide food for the living but also serve as medicines to many as well. These medicinal plants are major sources of live saving bio-chemicals and some other essential chemical substances for the benefit of mankind. The need to be and remain healthy, to be economically productive, naturally viable cannot be over stressed. The negative side effects, high cost, unavailability and inaccessibility of synthetic medicines, to a larger percentage of persons, have left man with no choice than to go back to green medicines in other to remedy his life threatening afflictions [4]. It is also an established fact that some parts of plants, possessed series of phytochemicals and phyto-nutrients properties which reveals diverse pharmacological and biological responses and diversities with reference to human health. Man's errors as mentioned above, in handling some of nature's endowment has altered the balance in natural orders or the ecosystem thereby leading to: Emerging new infectious, chronics and conventional drugs resistance cardiovascular diseases [5]. Genes and environment interacts and this interaction couple with our life styles are capable of causing chronic diseases non-communicable diseases (NCD) such as cancer, diabetes and blood pressure. These diseases are in epidemic numbers, and the epidemics are expected to continue growing if nothing is done to curtail them. This is mainly due to an increasing proportion of aged people, with reckless life styles such as inactivity, alcoholism, tobacco addiction, obesity, bad dieting and exposure to harsh radiation regardless of the gender [6].

The word Cancer, is a broad term referring to a class of diseases characterized by abnormal cells growths that invade healthy cells in the body [7]. Breast cancer for instance, starts in the cells of the breast as a group of cancer cells that can then invade surrounding tissues or spread (metastasize) to other areas of the body just like prostate cancer starts at the abdorminal region of the body and later metastasize to other parts of the body [8]. What Causes Cancer to Formulate is the abnormality in cell development in the body: Cancer begins in the cells which are the basic building blocks that make up tissue [9]. These tissues are found in the breast, prostate and other parts of the body. Sometimes, the process of cell growth goes wrong and new cells form when the body doesn't need them and old or damaged cells do not die as they should [10]. When this occurs, a build up of cells often forms a mass of tissue called a lump, growth, or tumour [9]. Breast cancer for instance, occurs when malignant tumours formulate in the breast just like prostrates cancer occurs around the abdominal region of the human body by the formation of malignant growth [11]. These cells can spread by breaking away from the original tumour and entering blood vessels or lymph vessels, which branch or spread into tissues throughout the body. When cancer cells travel to other parts of the body and begin damaging other tissues and organs, the process is called metastasis.

Cancer as an abnormal health condition remains one of the leading causes of morbidity and mortality in the entire universe [12]. Cancer is the second leading cause of death amongst the non-communicable diseases after cardiovascular disease being the first. Chemotherapy is routinely used for cancer treatment. Since cancer cells lose many of the regulatory functions present in normal cells, they continue to divide when normal cells do not. This feature makes cancer cells susceptible to chemotherapeutic drugs. Approximately five decades of systemic drug discovery and development have resulted in the establishment of a large collection of useful chemotherapeutic agents [13].

Diabetes is defined as an abnormal health condition that is caused by impaired insulin and Leptin sensitivity [14]. It is also commonly believed by many professionals and highly respected medical practitioners 'that this health condition is caused by excess sugar or glucose in the blood and that is the major reason it is often called high blood sugar. In simple terms, diabetes is an abnormality that means having excess glucose or sugar in the blood [14]. Even though your blood actually needs some amount of glucose for energy supply to keep you strong, too much of it could be disastrous to your health. Glucose comes from the food human ingest into their body, from the liver and also from our muscles. The blood then carries the same glucose into all parts (cells) of the body. Insulin is a chemical or hormone secreted or produced by the pancreas into the blood which controls the rate at which glucose gets into the body cells. If your system does not have enough insulin required for controlling this processes, or if the available insulin does not work optimally as expected, then the glucose will not get into your body cells. Instead, it will remain in your blood cells rather accumulating. Eventually, it will becomes high and at this stage it is said "you have high blood sugar" or diabetes [14].

Blood pressure is the measure of the force of blood pushing against blood vessel walls [15]. The heart pumps blood into the arteries (blood vessels), which carry the blood throughout the body. High blood pressure, also called hypertension, is dangerous because it overwork the heart by pumping blood harder to the body and contributes to hardening of the arteries, or atherosclerosis, to stroke, kidney disease, and to the development of other cardiovascular diseases. Blood pressure is a ratio ideally, we should all have a blood pressure below 120 over $80(120 / 80)$. This is the ideal blood pressure for people wishing to have good health. At this level, we have a much lower risk of heart diseases or stroke [16]. This blood pressure level is what is called optimal or normal blood pressure level.

Blood pressure reading has a top number called systolic and bottom number called diastolic. The ranges are: Normal: Less 
than 120 over 80 (120/80) Pre-hypertension: 120-139 over 8089 is called Stage 1 high blood pressure: $140-159$ over $90-99$ is called Stage 2 high blood pressure: 160 and above over 100 and above and High blood pressure in people over age 60: 150 and above over 90 and above [12]. The real causes of high blood pressure are not accurately known, it is attributed to several factors which includes: Smoking, excess alcohol consumption, stress, older age, genetics and or family history [17-20].

A Stroke is consequential results of A cardiovascular disorder especially hypertension which occurs when the blood supply to the brain is interrupted or reduce. When this happened, it deprives the brain of oxygen and nutrients, which are capable of causing the brain cells to die. A stroke may be caused by a blocked artery and it is called ischemic stroke or by the leaking or bursting of a blood vessel and is called hemorrhagic stroke while some people may experience only a temporary disruption of blood flow to their brain and this type of stroke is called transient ischemic attack (TIA) The signs and symptoms of strokes are: Having trouble with speaking and understanding [17,21-27]. You may experience confusion. You may slur your words or have difficulty understanding speech, Having Paralysis or numbness of parts of your body like; the face, arm or leg, Developing sudden numbness, weakness or paralysis especially on one side of your body, If one of your arm begins to fall when you Try to raise both your arms over your head at the same time, you may be having a stroke. Similarly, one side of your mouth may droop when you try to smile, Having Trouble with seeing in one or both eyes. You may suddenly have blurred or blackened vision in one or both eyes, and you may see double, having Headache. A sudden, severe headache, which may be accompanied by vomiting, dizziness or altered consciousness, may indicate you're having a stroke, Having Trouble with walking. You may stumble or experience sudden dizziness, loss of balance or loss of coordination.

\section{Materials and Methods}

Materials all materials were obtained from federal cereal research institute Badeggi Bida in Niger state and department of agric and bio-resources engineering futminna.

\section{Method}

\section{Pre-Treatment and Processing of Raw Materials}

Pre-treatment and processing of bitter leaves (Vernonia amygdalina): The fleshly harvested young and matured leaves of Vernonia amygdalina also called bitter leaves were collected from the farm and washed thoroughly with distilled water to remove impurity. The washed freshly harvested leaves were then dried indoor for 168 hrs (seven days) after which, they were crushed into smaller sizes and grinded to obtained finely divided particles called Vernonia powder.

Pre-Treatment and Processing of Ginger Rhizomes (Zingiber Officinale): Freshly harvest Ginger rhizomes were collected and washed thoroughly to remove unwanted materials. Then the thoroughly washed rhizomes were then sliced to aid drying, and dried for $240 \mathrm{hrs}$ (ten days). The dried mesocarp was then crushed and further grinded into very fine powder.

Pre-Treatment and Processing of Guava (Psidium guajava): Freshly harvested guava leaves, matured fruits and pills were collected. The collected young and old leaves were washed thoroughly in order to remove unwanted materials from it. The washed leaves were then dried for $168 \mathrm{Hrs}$ indoor. The dried leaves were crushed. The matured Guava fruits were sliced and dried for $240 \mathrm{Hrs}$ indoor. The pills were crushed and dried for $240 \mathrm{Hrs}$ also under the same condition as the two components. The three crushed components (leaves fruits and pills) were blended and grinded to form a very fine powder called guava powder.

Pre-treatment and processing of Moringa (Moringa oleifera): The freshly harvest leaves of moringa olfera and the matured fruits were collected. The matured dried fruits were piled up using a mortar to get the hard seeds the hard seeds were also pitted to remove the dried harsh dried cover from it. The seeds were then crushed. The young harvested leaves were also washed and dried for $168 \mathrm{Hrs}$ (seven days). The dried leaves were crushed and blended with the crushed seeds and grinded together to form one component called moringa powder.

Pre-treatment/processing of turmeric (curcuma longa): The fresh Turmeric was purchased and washed thoroughly to remove impurities. The washed turmeric was then sliced to aid drying. The sliced were then dried for $240 \mathrm{hrs}$ after which the dried one was crushed and grinded into fine powder.

Pre-treatment/processing of scent leaf (Ocimum gratissimum): The fleshly harvested scent leaves was collected from the farm and washed thoroughly with distilled water to remove any impurity from it. The washed fresh scent leaves was then dried under normal atmospheric condition (away from sunlight or room temperature) for $168 \mathrm{hrs}$ (seven days). The dried scent leaves was then crushed and grinded to obtained very finely divided powder called scent leaves powder.

Pre-treatment /processing of pawpaw leaves and fruits (Carica papaya): The fleshly harvested pawpaw leaves and fruit were collected from the Carica papaya plant and washed thoroughly with distilled water to remove impurities from it. The washed fresh leaves and fruits were then sliced and dried under normal atmospheric condition (away from sunlight that is at room temperature) for $336 \mathrm{hrs}$ (fourteen days). The dried leaves were then crushed and grinded to obtained very fine powder called pawpaw powder

\section{sample preparation and formulation of multi-functional flora composite}

Preparation of Samples: The grinded powder of ginger obtained from pre-treatment and processing of raw materials was sieved using a very fine mesh to obtain a finely divided granulated powder. The same procedure was followed for the remaining six plants. The powders were then measured into 


\section{Engineering Technology Open Access Journal}

seven portions at the ratio of 3:3:3:2:2:2:1 (300g, 300g, 300g, 200g, 200g, 200g, 100g) for Ginger, Turmeric, Moringa oleifera Scent leafs, Guava leafs And Pawpaw leafs respectively. This is due to their relative essentiality to the objective and aim of this research from literature. These powder portions formed the samples of interest (Figure 1-7).
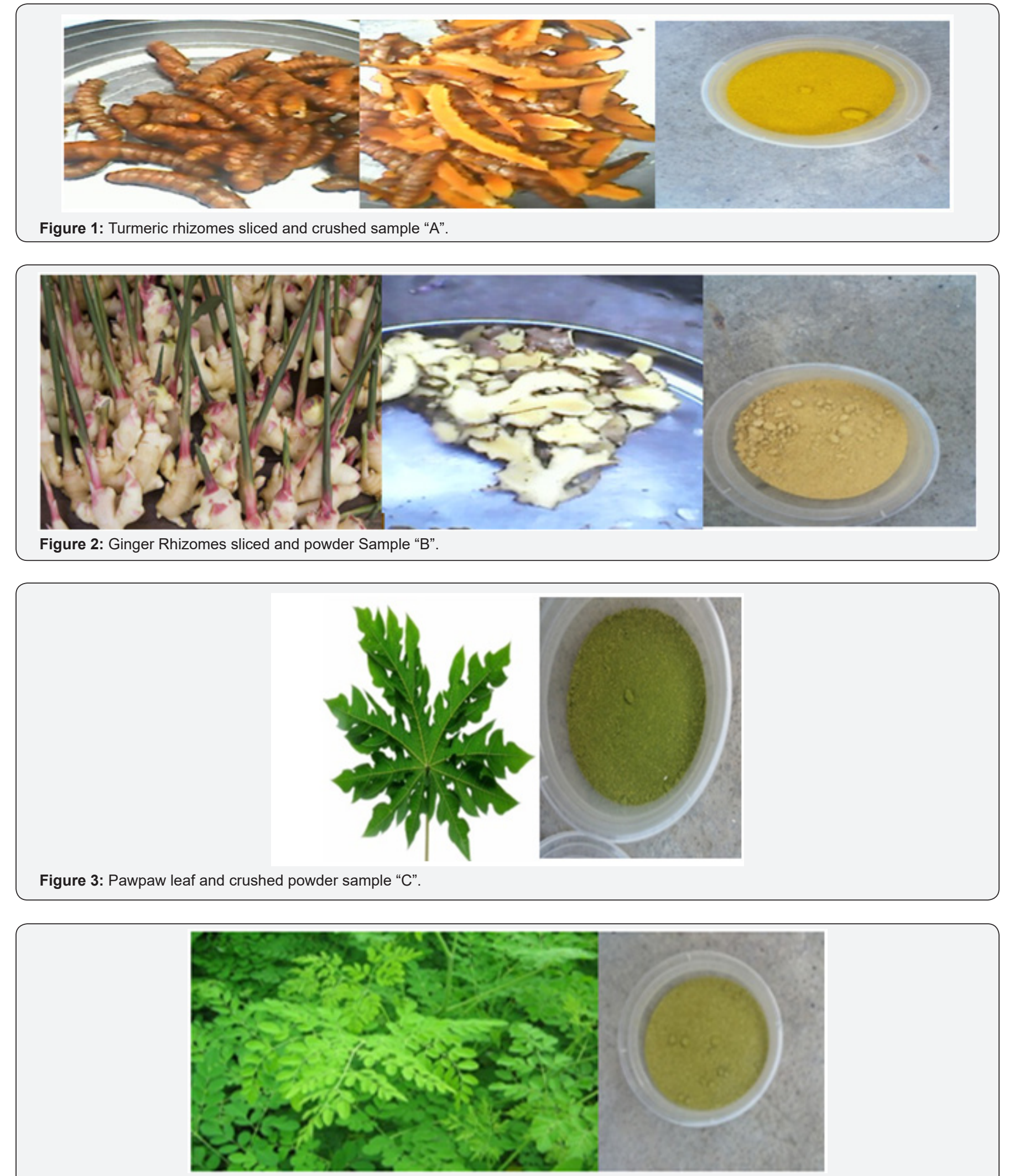

Figure 4: Moringa oleifera leaf and crushed powder sample "D". 


\section{Engineering Technology Open Access Journal}

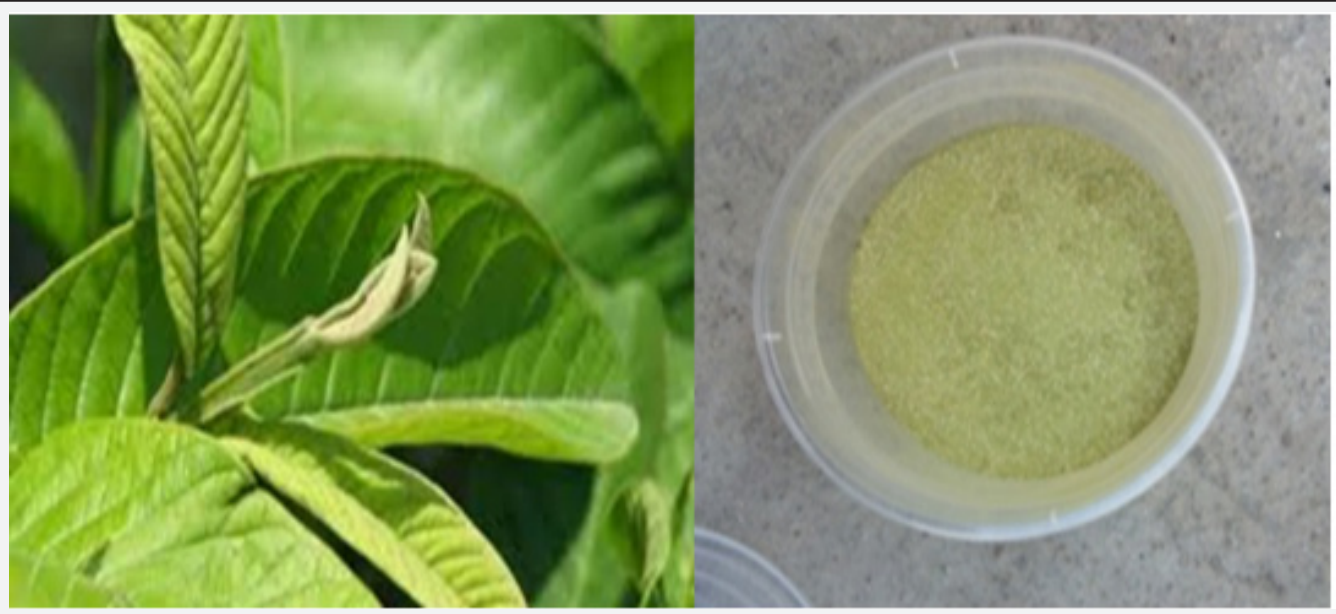

Figure 5: guava leaf and crushed powder sample "E".
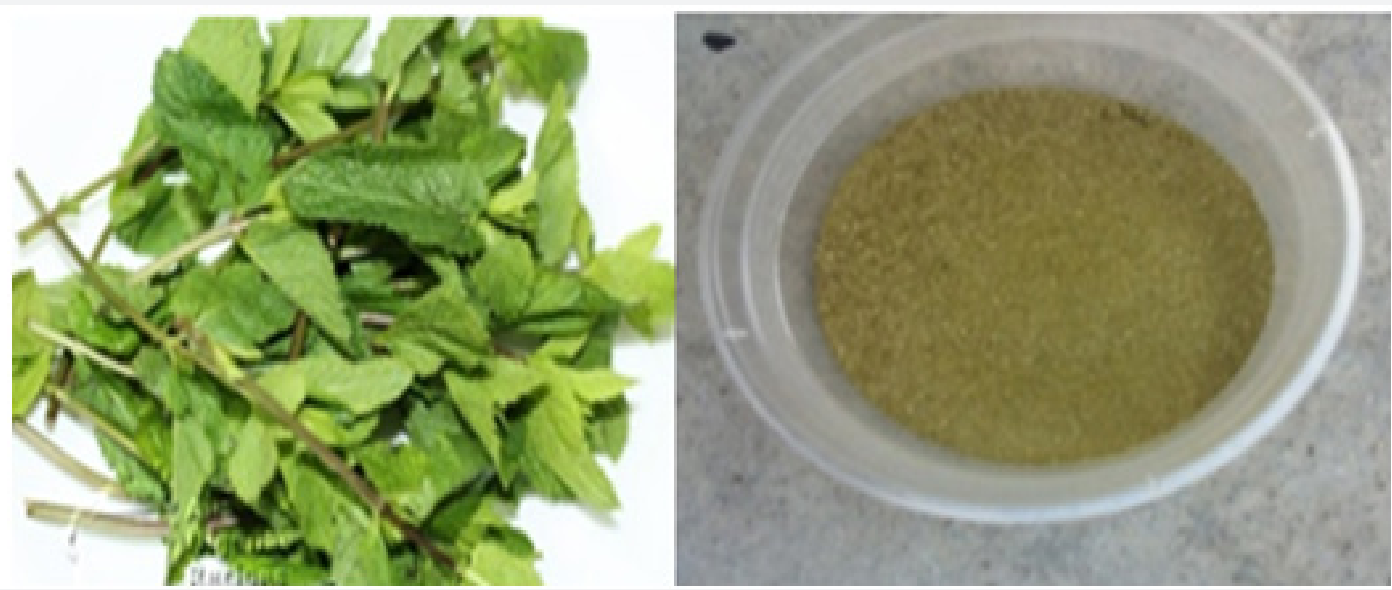

Figure 6: scent leaf and crushed powder "F".

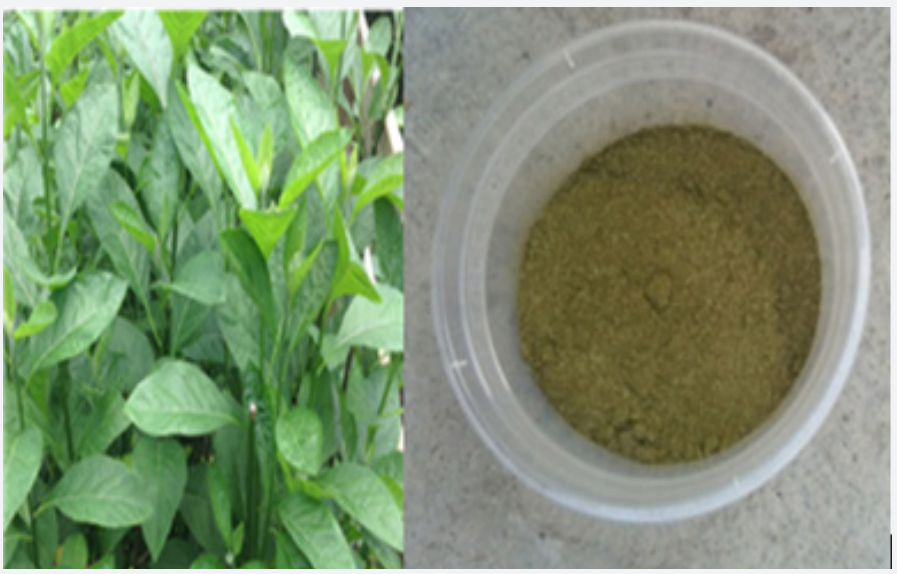

Figure 7: bitter leaf and crushed powder sample "G".

Formulation of A multifunction hybrid flora composite by simple combination of samples: The seven samples in the ratio of 3:3:3:2:2:2:1, as shown above for Ginger Rhizomes Powder, Turmeric Rhizomes Powder, Moringa Oleifera Leaf Powder, Scent Leafs Powder, Guava Powder, Bitter Leaf Powder and Pawpaw leaf powder respectively, were blended together using a blender in order to obtain homogenous multifunctional hybrid flora composite which total to 1600 grams. This quantity was dived into two. One of the portion ( 800 grams forms the raw multifunctional flora composite) which gave higher quantities of bioactive composition according to the results of the analysis (Figure 8). 


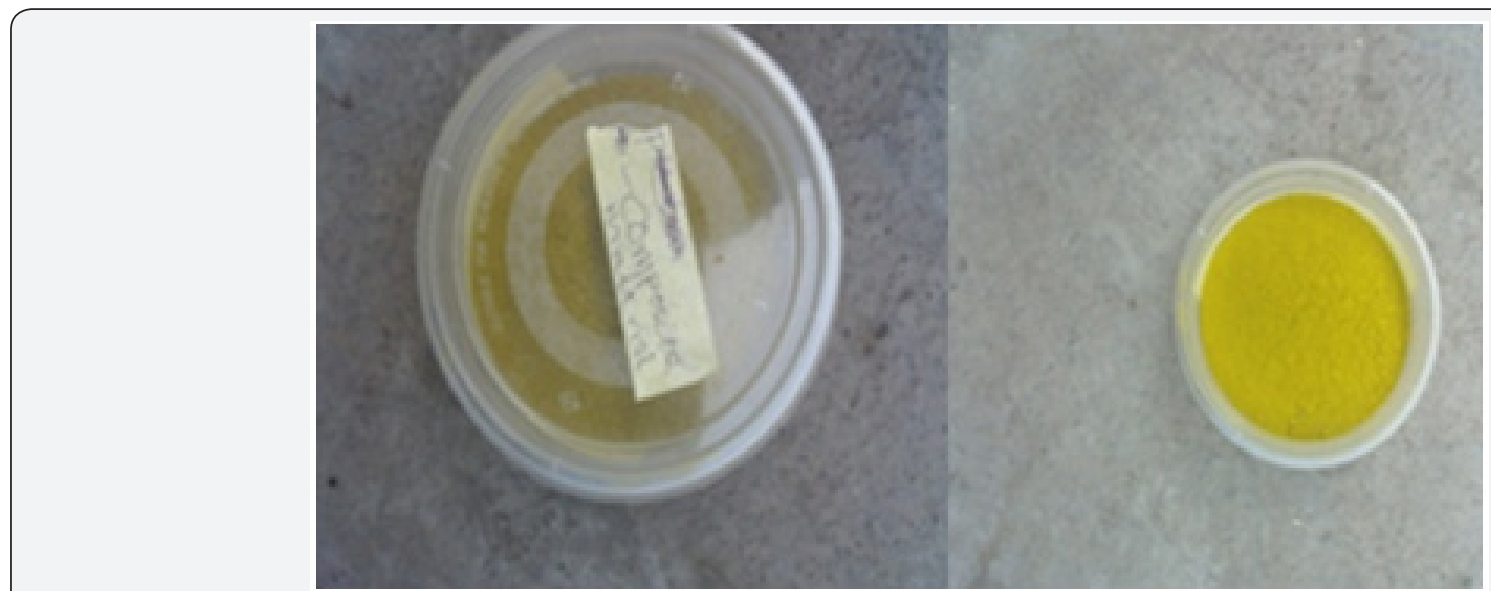

Figure 8: multifunctional flora composite

Formulation of a multi-functional flora composite using filtration and evaporation:The seven samples of plants' powders were blended together after appropriate measurements as shown above. The remaining $800 \mathrm{~g}$ of raw Multifunctional flora composite was hydrolyzed (that is, $500 \mathrm{~mL}$ of water was added to It.) and stirred intermittently within $72 \mathrm{hrs}$ and filtered using a very fine mesh. The filtrate was then evaporated at $42.50 \mathrm{C}$ using fan circulated evaporator for two weeks and the paste was collected and dried using cool air and ventilates room for three days (Figure 9). The evaporation rate was slow because, the temperature at which the evaporator was set is below the boiling point of water $(1000 \mathrm{C})$. These is because, the secondary metabolites are thermo-labile and excess heat will either denatured/ deactivate or make most of them escape completely or transform to other component. The dried composite material was then grinded and packaged.
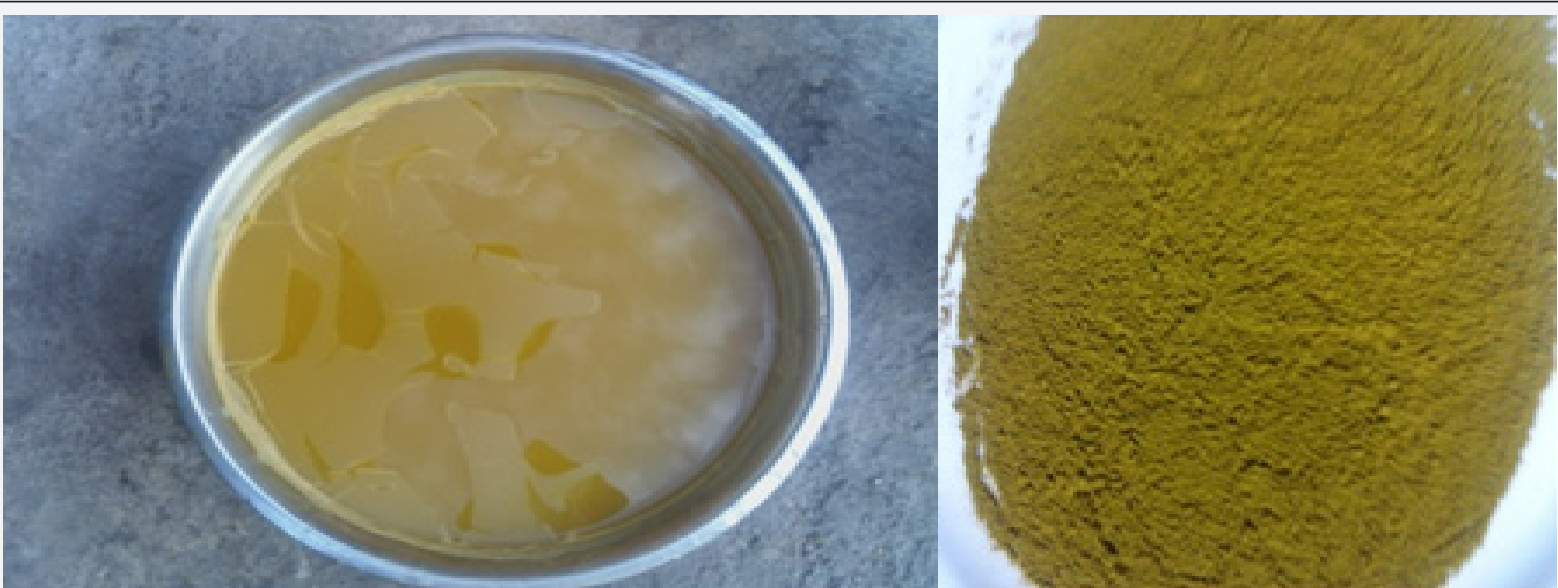

Figure 9: multifunctional hybrid flora composit

Analysis was carried out in federal cereal research institute badegi bidda niger state.

\section{Results and Discussions}

\section{Minerals analysis of samples and flora composite}

The result in Table 1 above is that of mineral analysis of samples and composite pellet. A mineral by definition, is a chemical element required as an essential nutrient by organisms to perform functions necessary for life. Minerals are of the earth's origin and cannot be made by living organisms. Plants get minerals elements from the soil. Most of the minerals in human diets come from eating plants and animals source food or from drinking water. As a group, minerals are one of the four groups of essential nutrients, the others of which are vitamins, essential fatty acids, and essential amino acids. The five major minerals in the human body are calcium $(114.43 \mathrm{mg} / 100 \mathrm{~g})$, phosphorus (121.94mg/100g), potassium (224.24mg.100g), sodium (30.55mg/100g, and magnesium (99.75mg/100g). All the remaining elements in a human body are called "trace elements". The trace elements that have specific biochemical functions in the human body are sulphur, iron $(11.37 \mathrm{mg} / 100 \mathrm{~g})$, chlorine, cobalt, copper $(1.46 \mathrm{mg} / 100 \mathrm{~g})$, zinc $(10.32 \mathrm{mg} / 100 \mathrm{~g})$, manganese $(1.71 \mathrm{mg} / 100 \mathrm{~g})$, molybdenum, iodine and selenium on average. Minerals are inorganic nutrients, usually required in small amounts from less than $1 \mathrm{mg}$ to $2500 \mathrm{mg}$ per day, depending on the mineral element in question. 
Table 1: showing results of minerals analysis of ginger, turmeric, bitter leaves, scent leaves, guajava, moringa leaves, pawpaw and their average values.

\begin{tabular}{|c|c|c|c|c|c|c|c|c|c|}
\hline 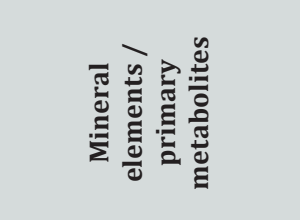 & 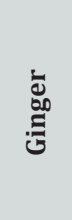 & $\stackrel{U}{\Xi}$ & 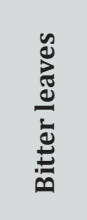 & 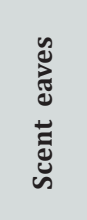 & 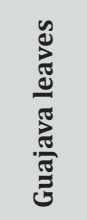 & 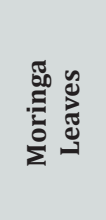 & 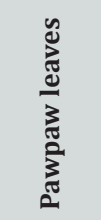 & 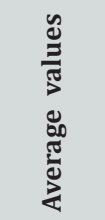 & تृ \\
\hline Calcium (mg/100g) & 16 & 228.8 & 13.11 & 64.8 & 18 & 440 & 20.31 & 114.43 & 126.05 \\
\hline Potassium (mg/100g) & ND & 551.3 & 9 & 86.24 & 417 & 324.01 & 182.11 & 224.24 & 382.4 \\
\hline Magnesium (mg/100g) & ND & 179.8 & 19.01 & 88.25 & 22.01 & 368 & 21.17 & 99.75 & 74.35 \\
\hline Phosphorus (mg/100g) & 34 & 543.9 & ND & 21.65 & 40 & 204 & 10 & 121.94 & 120.9 \\
\hline Iron (mg/100g) & 0.6 & 1.1 & 25.58 & 23.37 & 0.28 & 28.3 & 0.35 & 11.37 & 96.11 \\
\hline Zinc (mg/100g) & 0.36 & 59.7 & 2.07 & 6.86 & 0.25 & 2.29 & 0.72 & 10.32 & 12.94 \\
\hline Manganese (mg/100g) & 0.23 & 2.3 & 1.03 & 4.63 & 0.2 & ND & 3.57 & 1.71 & 1.56 \\
\hline Sodium (mg/100g) & 13 & 94.7 & 12.02 & 84.11 & 2.01 & ND & 8.01 & 50.55 & 96.12 \\
\hline Nickel (mg/100g) & ND & 34 & 3.01 & 5.16 & 1.02 & ND & 0.07 & 6.18 & 6.86 \\
\hline Copper (mg/100g & ND & 0.6 & 2.75 & 5.69 & ND & 0.57 & 0.32 & 1.45 & 1.1 \\
\hline
\end{tabular}

The basic functions performed by minerals elements are: they are structural components of the body tissues; they are involved in the maintenance of acid-base balance and in the regulation of body fluids, in transport of gases and in muscle contractions. Having good Knowledge of the biochemistry and functions of the mineral elements in human body, animal system and plants tissues will certainly assist plant physiologists and breeders or geneticists, to give priority to mineral elements of essential functions and importance in the health and diseases of humans and animals also when selecting desirable traits in diets. Consequently, this will also help the food industries, dieticians, human and animal nutritionists, and veterinarians to be aware fully equipped with the best knowledge of the effects of different processing methods/techniques on these important mineral elements and their applications to meet certain health and nutritional demands of the bio-systems or tissues of either plants or animals. As an example, any one with very good knowledge of sodium functions and chemistry will know that: high dietary sodium is implicative and said to be responsible in and for cardiovascular and renal disorders especially rising blood pressure level. Hence, high dietary sodium is often discouraged by these human diets and health experts in patients who have suffered from or are prone to hypertension. Also, knowledge of the importance of the mineral elements in plants is essential as the global trend in nutrition and medicine is shifting from processed and synthetic consumables towards the consumption of green plant as foods such as fruits and vegetables and medicinal plants (phyto-medicines like this very multifunctional flora composite pellets) respectively, because the plant kingdom is reported to be full of large numbers of beneficial substances to both human and animal health.

Calcium (Ca) Calcium as an essential element with an average value of 114.43 milligrams per hundred grams of sample and composite flora values of 126.05 miligrams per hundred grams, plays its roles as a constituent of bones and teeth formations, regulation of nerves and muscles functions in living cells. In blood coagulation, calcium functions as an activator by activating the conversion of prothrombin to thrombin and also takes part in milk clotting. It plays a vital role in enzyme activation also. Calcium activates large number of enzymes such as adenosine triphosphatase (ATPase), succinic dehydrogenase and lipase. Calcium is also required for membrane permeability; it is involved in muscle contraction, normal transmission of nerves impulses and in neuromuscular excitability. Reduced extracellular blood calcium increases the irritability of nerves tissues, and a very low level may cause spontaneous discharges of nerves impulses leading to tetany (a condition marked by intermittent muscular spasms, caused by malfunction of the parathyroid glands and a consequent deficiency of calcium) and convulsions. Calcium absorption requires calcium-binding proteins and is regulated by vitamin $\mathrm{D}$, sunlight, parathyroid hormone and thyrocalcitonin. Thyrocalcitonin decreases plasma calcium and phosphate levels whereas parathyroid hormone increases them. Dietary calcium and phosphorus are absorbed mainly in the upper small intestine, particularly the duodenum and the amount absorbed is dependent on source, calcium-phosphorus ratio, intestinal $\mathrm{pH}$, lactose intake and dietary levels of calcium, phosphorus, vitamin D, iron, aluminium, manganese and fat. The greater the need for calcium in the body, the more efficient the absorption of it into the system. The intake or absorption of calcium and phosphorus to the body system is often facilitated by a low intestinal $\mathrm{pH}$ which is necessary for their solubility and thus normal gastric secretion of hydrochloric acid or $\mathrm{H}^{+}$is necessary for efficient absorption. Lactose also enhances the absorption of calcium apart from low $\mathrm{pH}$ duodenum. The deficiency of calcium in children causes rickets due to insufficient calcification by calcium phosphate of the bones in growing children. The bones therefore remain soft and deformed by the body weight. In adults, it causes osteomalacia, a generalized demineralization of bones. It may also contribute 
to osteoporosis, a metabolic disorder resulting in decalcification of bone with a high incidence of fracture, that is, a condition where calcium is withdrawn from the bones and the bones become weak and porous and then breaks. Calcium deficiency also affects the dentition of both children and adult. Toxicity symptoms occur with excess absorption due to hypervitaminosis D or hypercalcaemia due to hyperparathyroidism, or idiopathic hypercalcaemia. Excess calcium depresses cardiac activity and leads to respiratory and cardiac failure; it may cause the heart to stop in systole, although, normally, calcium ions increase the strength and duration of cardiac muscle contraction.

Phosphorus (P) Phosphorus as an essential mineral element from Table 2 above, with an average value of 121.94 milligrams per hundred grams and 120.90 milligrams per hundred grames of samples, is located in every cell of the body and is vitally concerned with many metabolic processes, including those involving the buffers (a solution which resists changes in $\mathrm{pH}$ when acid or alkali is added to it) in body fluids. The major roles of phosphorus are that: It functions as a constituent of bones, teeth, adenosine triphosphate (ATP), phosphorylated metabolic intermediates and nucleic acids. It plays buffering roles. That is phosphate buffers, functions in the formation of high energy compounds, that is, adenosine triphosphate (ATP) and is also involved in the synthesis of phospholipids and phosphoproteins. Practically, every form of energy exchange inside living cells involves the forming or breaking of high-energy bonds that link oxides of phosphorus to carbon or to carbon-nitrogen compounds. Vitamin D is said to be involved in the control of phosphorus absorption and serum levels are regulated by kidney re-absorption. Phosphorus is an essential macronutrient for plants and one of the three nutrients generally added to soils in fertilizers because of its vital role of energy transfer in living organisms such as plants and animals. Decrease in serum phosphorus is found in rickets, hyperparathyroidism, De Toni-Fanconi Syndrome. Deficiency disease or symptoms in children causes rickets and in adults, it causes osteomalacia. Increase in serum phosphorus is found in chronic nephritis and hypoparathyroidism. Toxicity disease or symptoms include low serum Ca $2^{+}$: P ratio. It may also lead to bone loss. Sources of phosphorus include phosphate food additives, green leafy vegetables and fruits, especially banana.

Table 2: showing results of nutritional analysis of ginger, turmeric, bitter leaves, scent leaves, guajava, moringa leaves, pawpaw and their average values.

\begin{tabular}{|c|c|c|c|c|c|c|c|c|c|}
\hline 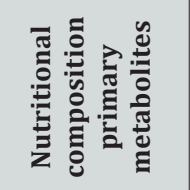 & 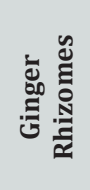 & 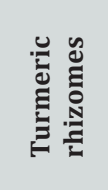 & 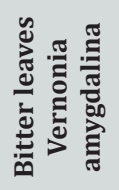 & 蛋 & 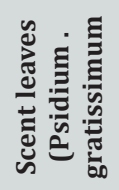 & 营 & 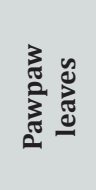 & 冚 & 현 \\
\hline $\begin{array}{c}\text { Carbohydrate } \\
(\%)\end{array}$ & 17.79 & 67.91 & 57.3 & 14.33 & 64.97 & 38.24 & 16.92 & 39.64 & 48.32 \\
\hline $\begin{array}{l}\text { Energy value } \\
\text { (Kcal.) }\end{array}$ & 80.07 & 333.41 & 320.44 & 68 & 390.5 & 205.01 & 58.78 & 208.03 & 286.11 \\
\hline $\begin{array}{c}\text { Crude } \\
\text { proteins (\%) }\end{array}$ & 1.83 & 9.48 & 22.05 & 2.57 & 8.47 & 27.2 & 0.47 & 10.3 & 10.98 \\
\hline $\begin{array}{l}\text { Ash content } \\
(\%)\end{array}$ & 0.89 & 9.67 & 9.23 & 5.75 & 13.6 & 9.79 & 2.41 & 10.33 & 7.64 \\
\hline $\begin{array}{c}\text { Moisture } \\
\text { content (\%) }\end{array}$ & 10.9 & 6.72 & 18.16 & 15.22 & 14.41 & 10.89 & 16.19 & 13.21 & 17.78 \\
\hline $\begin{array}{c}\text { Fat (oil) } \\
\text { content (\%) }\end{array}$ & 0.76 & 2.48 & 2.27 & 0.97 & 7.5 & 2.31 & 0.26 & 2.36 & 5.53 \\
\hline $\begin{array}{c}\text { Vitamins } \\
\text { content (\%) }\end{array}$ & 37 & 3.45 & 2.67 & 32.82 & 0.95 & 0.69 & 0.063 & 11.09 & 15.91 \\
\hline $\begin{array}{c}\text { Fibre content } \\
(\%)\end{array}$ & 7.01 & 4.23 & 8.86 & 5.4 & 9.5 & 9.2 & 1.87 & 6.58 & 7.27 \\
\hline
\end{tabular}

Sodium (Na) with an average value of 50.55 milligrams per hundred grams and composite value of 96 milligrams per hundred grams of sample, is the principal cation in extracellular fluids. It regulates plasma volume and acid-base balance, involved in the maintenance of osmotic pressure of the body fluids, preserves normal irritability of muscles and cell permeability, sodium also activates nerves and muscles' functions and involved in $\mathrm{Na}+\mathrm{K}+$-ATPase, maintenance of membrane potentials, transmission of nerves impulses and the absorptive processes of monosaccharide, amino acids, pyrimidines, and bile salts. The changes in osmotic pressure are largely dependent on sodium concentration. Its metabolism is regulated by aldosterone. Commonly used vegetable foodstuffs do not contain sufficient quantities of sodium to meet the animal's dietary need. This inadequacy is compensated for by including sodium chloride, common salt, in their diet or by allowing them to consume salt ad libidum. Sodium is readily absorbed as the sodium ion and circulates throughout the body. Excretion occurs mainly through the kidney as sodium chloride or phosphate. There are appreciable losses in perspiration, and 
the quantities lost by this route vary rather markedly with the environmental humidity [28-33]. Increased level of sodium in the serum is called hypernatraemia and this occurs in Cushion's disease, administration of adrenocorticotropic hormone (ACTH), administration of sex hormones, diabetes insipidous and after active sweating. Excessive intake of sodium chloride may result in salt toxicity which is mainly caused by sodium ion, since sodium acetate or sodium propionate affects the animals in a manner similar to that of sodium chloride.

Potassium (K) with average value of 224.24 milligrams per hundred grams and composite value of 382.40 milligrams per hundred grams of samples is the principal cation in intracellular fluid and functions in acid-base balance, regulation of osmotic pressure, conduction of nerves impulses, muscles contractions especially the cardiac muscles, cell membrane function and $\mathrm{Na}+$ / $\mathrm{K}+-$ ATPase. Potassium as a mineral element is also required during glycol-genesis (the formation of glycogen from sugar). It also helps in the transfer of phosphate from ATP to pyruvic acid. Its metabolism is regulated by aldosterone [34]. Hyperkalaemia is increased level in serum potassium and this occurs in Addison's disease, advanced chronic renal failure, shock and dehydration. Toxicity disease or symptoms include dilatation of the heart, cardiac arrest, small bowel ulcers. Hypokalaemia is low level of serum potassium and this occurs in diarrhoea, metabolic alkalosis and familial periodic paralysis. Deficiency disease or symptoms of potassium occurs secondary to illness, functional and structural abnormalities including impaired neuromuscular functions of skeletal, smooth, and cardiac muscle, muscular weakness, paralysis and mental. Potassium deficiency affects the collecting tubules of the kidney, resulting in the inability of the kidney's colleting tubules to concentrate urine, and also causes alterations of gastric secretions and intestinal motility. The rapidly growing animals apparently have a higher requirement for potassium, and increasing the protein level increases the requirement. Plant products contain many times as much potassium as sodium.

Magnesium (Mg) Magnesium as a mineral element and as a primary metabolite with an average value of 99.75 milligrams per hundred grams and composite value of 74.35 milligrams per hundred grams of samples is an active component of several enzymes in living systems within which thymine pyrophosphate is a cofactor. Oxidative phosphorylation is greatly reduced in the absence of magnesium. MAgnessium is also an essential activator for the phosphate-transferring enzymes myokinase, diphophopyridine nucleotide kinase, and creatine kinase. It also activates pyruvic acid carboxylase, pyruvic acid oxidase, and the condensing enzyme for the reactions in the citric acid cycle. It is also a constituent of bones, teeth, enzyme cofactor or kinases [35-38]. The health status of the digestive system and the kidneys significantly influence magnesium status. Magnesium is absorbed in the intestines and then transported through the blood to cells and tissues. Approximately one-third to one-half of dietary magnesium is absorbed into the body. Gastrointestinal disorders that impair absorption such as Crohn's disease can limit the body's ability to absorb magnesium. These disorders can deplete the body's stores of magnesium and in extreme cases may result in magnesium deficiency. Deficiency diseases or symptoms are secondary to mal-absorption or diarrhoea, alcoholism. Toxicity disease or symptoms of magnesium deficiency in humans include depressed deep tendon reflexes and respiration. Sources include leafy green vegetables (containing chlorophyll).

Copper $(\mathrm{Cu})$ as a trace element with an average value of 1.41Milligrams per hundred grams and composite value of 1.10 milligrams per hundred grams of sample is a constituent of enzymes like cytochrome-c oxidase, amine oxidase, catalase, peroxidase, ascorbic acid oxidase, cytochrome oxidase, plasma monoamine oxidase, erythrocuprin (ceruloplasmin), lactase, uricase, tyrosinase and cytosolic superoxide dismutase. Cupper plays a role in iron absorption it is an essential micro-nutrient necessary for the haematologic and neurologic systems (blood formation and regulations), It is necessary for the growth and formation of bone, formation of myelin sheaths in the nervous systems, cupper helps in the incorporation of iron in haemoglobin, assists in the absorption of iron from the gastrointestinal tract (GIT) and in the transfer of iron from tissues to the plasma. Increased levels of copper are seen in acute infections and in chronic conditions such as cirrhosis, rheumatoid arthritis and in post-operative stages. Increased level is also found in malnutrition. Clinical disorders associated with $\mathrm{Cu}$ deficiencies include anaemia, bone disorders, neonatal ataxia, depigmentation and abnormal growth of hair, fur or wool, impaired growth and reproductive performance, heart failure and gastrointestinal disturbances. The incidence of these disorders varies widely among animal species and human beings. Cu deficiency has also been associated with cardiac hypertrophy and sudden cardiac failure. Excess dietary $\mathrm{Cu}$ causes an accumulation of $\mathrm{Cu}$ in the liver with a decrease in blood haemoglobin concentration and packed cell volume. Liver function is adversely affected in copper poisoning. Jaundice results from erythrocyte haemolysis and this may lead to death unless treatment is started.

Iron (Fe) as a mineral element present in this composite flora material with an average value of 11.37 milligrams per hundred grams and 96.11milligrams per hundred grames of sample, functions as haemoglobin in the transport of oxygen. In cellular respiration, it functions as essential component of enzymes involved in biological oxidation such as cytochromes. Fe is an important constituent of succinate dehydrogenase as well as a part of the haeme of haemoglobin $(\mathrm{Hb})$, myoglobin and the cytochromes. Iron is required for proper myelination of spinal cord and white matter of cerebellar folds in brain and is a cofactor for a number of enzymes involved in neurotransmitter synthesis. Iron is involved in synthesis and packaging of neurotransmitters, their uptake and degradation into other iron-containing proteins may directly or indirectly alter brain function. (Iron exists in the blood mainly as haemoglobin in the erythrocytes and as transferrin in the plasma. It is transported as transferrin; stored 
as ferritin or haemosiderin and it is lost in sloughed cells and by bleeding. Fe is required for making haemoglobin and it is a pro-oxidant which is also needed by microorganisms for proliferation. Biologically important compounds of iron are haemoglobin, myoglobin, cytochromes, catalases and peroxidise. Deficiency disease or symptoms include anaemia, (hypochromic, microcytic). Fe deficiency has been reported to have a role in brain development and in the pathophysiology of restless legs. Also, Fe deficiency is associated with alterations in many metabolic processes that may impact brain functioning, among whom are neurotransmitter metabolism, protein synthesis and organogenesis. Sources include red meat, spleen, heart, liver, kidney, fish, egg yolk, nuts, legumes, molasses, iron cooking ware, dark green leafy vegetables.

Manganese $(\mathrm{Mn})$ with an average value of 1.71 milligrams per hudred grams and composite value of 1.56 milligrams per hundred grams of sample is a cofactor of hydrolase, decarboxylase, and transferase enzymes. It is involved in glycoprotein and proteoglycan synthesis and is a component of mitochondrial superoxide dismutase.

Manganese is a co-factor in phosphohydrolases and phosphotransferases involved in the synthesis of proteoglycans in cartilage. $\mathrm{Mn}$ is a part of enzymes involved in urea formation, pyruvate metabolism and the galactotransferase of connective tissue biosynthesis. Mn activates several important enzyme systems and in this capacity it is required for the synthesis of acid muco polysaccharides, such as chondroitin sulphate, to form the matrices of bones and egg shells. Consequently skeletal deformities and defects in shell quality occur when the manganese intake is inadequate. Manganese deficiency presents with the following signs; in pigs, lameness, enlarged hock joints, and shortened legs, in cattle, leg deformities with over knuckling, in chicks, poults and ducklings, perosis or slipped tendon; and in chick embryos, nutritional chondro dystrophy. In laboratory animals, effects of deficiency include deformities of bone, poor growth, impaired reproduction, egg shell formation, and blood clotting. Mn overexposure reportedly may have an adverse effect on central nervous system (CNS) function and mood. Toxicity disease or symptoms by inhalation poisoning produces psychotic symptoms and Parkinsonism. Sources include whole grains, tea, legumes, nuts and seeds.

Zinc ( $\mathrm{Zn}$ ) with an average value of 10.32 milligrams per hundred grams and 12.94 milligrams per hundred grams of sample from the above table, is distributed widely in plant and animal tissues and occurs in all living cells. It functions as a cofactor (a substance (other than the substrate) whose presence is essential for the activity of an enzyme) and is a constituent of many enzymes like lactate dehydrogenase, alcohol dehydrogenase, glutamic dehydrogenase, alkaline phosphatase, carbonic anhydrase, carboxy peptidase, superoxide dismutase, retinene reductase, deoxyribonucleic acid (DNA) and ribonucleic acid (RNA)polymerase. Zn dependent enzymes are involved in macronutrient metabolism and cell replication. Carbonic an hydrase is present in erythrocytes, kidney tubules, gastrointestinal mucosa and glandular epithelium. The primary roles of zinc are mainly in cells replications and gene's expressions and in nucleic acid and amino acid metabolisms. Vitamins A and E metabolism and bioavailability are dependent on zinc status in the body. It is necessary for fertility of mice. It is also required for normal testicular development and for functions of the taste buds. It is needed for tissue repair and wound healings zinc plays a vital role in protein synthesis and digestion. It is also necessary for optimum insulin action as zinc is an integral constituent of insulin. Furthermore, zinc is an important constituent of plasma. In birds, zinc is required primarily for the growth and development of the skeleton, the formation and maintenance of epithelial tissue and for egg production. Excess calcium in diet however hastens the onset of para keratosis. Formation of zinc fingers in nuclear receptors for steroid-thyroid, calcitriol receptors, gene expression, essential in protein synthesis, involves in the storage and release of insulin, growth and repair of tissues, development of sex organs, needed in the enzymes required for the synthesis of DNA and RNA, mobilization of vitamin A from the liver and stabilization of cell membranes. It is present in meat and other protein foodstuffs, but intestinal absorption is affected by other dietary constituents. Absorbed zinc enters the liver where it is incorporated into zinc metalloenzymes and exported to peripheral tissue in plasma, bound to albumin.

\section{Results of nutritional analysis of samples and flora composites and their discussions}

Table 2 above shows the result of nutrients analysis of the seven samples and their nutritional compositions. The average is values as extracted from the table above are listed below: averaging from the seven plants, carbohydrate has $39.64 \%$, crudes proteins $10.30 \%$, ash content $7.33 \%$, moisture content $13.21 \%$, fat/oil $2.36 \%$, vitamins $11.09 \%$ and fibre content $6.58 \%$. Carbohydrate content from the table of results above, carbohydrate has an average content value of 39.64 percent and composite value of 48.32 percent. Carbohydrates are either complex sugar (starches) or simple sugars. The primary function of carbohydrate/sugar in the human body metabolism process is to provide energy to power the body for its activities.

The primary role of carbohydrates is to provide energy, as they are the body's main source of fuel, needed for physical activity, brain function and operation of the organs. All the cells and tissues in your body need carbohydrates, and they are also important for intestinal health and waste elimination. Once in the body, carbohydrates are easily converted to fuel. The digestive system changes carbohydrates into glucose, also known as blood sugar. Some glucose is used for energy and the rest is stored in the liver and muscles for later use. As your blood sugar rises, your pancreas pumps out more and more insulin, a hormone that tells cells to absorb glucose for energy supply or for storage. As cells absorb the glucose, blood sugar 
levels begin to fall, which signals the pancreas to start making glucagon, a hormone that tells the liver to release stored glucose. The two types of carbohydrates are simple and complex. Simple carbohydrates, also called simple sugars, include sugars founds in fruits, vegetables and milk, as well as sugars added during food processing. Complex carbohydrates, also called starches, include whole-grain breads and cereals, starchy vegetables and legumes. Most complex carbohydrates contain fibres, which helps digestive health and increases satiety, reducing overeating and weight gain. Stick with low-fat dairy products to reduce saturated fat and calories. Limit intake of foods with added sugars - these types of carbohydrates can lead to poor nutrition, tooth decay and weight gain consequently to obesity, diabetic, blood pressure and stroke.

Vitamins from the above table have an average value of 11.09 percent and a composite value of 15.91 percent of sample plays very important Roles in human body as nutritional components of this multifunctional hybrid component. Vitamins are a group of substances that are needed for normal cell function, growth, and development. There are 13 essential vitamins. This means that these vitamins are required for the body to work properly. Vitamins are organic compounds needed in small quantities by living tissues to sustain life. We need to take vitamins from food because the human body either does not produce enough of them or none at all. Each organism has different vitamin requirements. For example, vitamin C also called ascorbic acid, is a necessary nutritional needs for humans but not for dogs, because dogs can produce (synthesize) enough for its needs, while humans cannot. They are: Vitamin A, Vitamin C, Vitamin D, Vitamin E, Vitamin K, Vitamin B1 (thiamine), Vitamin B2 (riboflavin), Vitamin B3 (niacin), Pantothenic acid (B5), Biotin (B7) Vitamin B6, Vitamin B12 (cyanocobalamin) and Folate (folic acid and B9). These Vitamins are grouped into two categories such as: Fat-soluble vitamins which are stored in the body's fatty tissue. And the four fat-soluble vitamins are vitamins A, D, E, and K. These vitamins are absorbed more easily by the body in the presence of dietary fat. There are nine water-soluble vitamins. The body must use water-soluble vitamins right away. Any leftover water-soluble vitamins leave the body through the urine. Vitamin B12 is the only water-soluble vitamin that can be stored in the liver for many years. Selenium is also part and parcel of the body defence system that is the blood and proteins formations it is said to be the major constituent of vitamin E (Selenium (Se) Selenium is a constituent of glutathione peroxidise and also a constituent element of the entire defence system that protects the living organisms from the harmful actions of free radicals.

Organic selenium is more thoroughly reabsorbed and more efficiently metabolized than its inorganic equivalent, which is poorly resorbed and acts more as a prooxidant provoking glutathione oxidation and oxidative damage to the deoxyribonucleic acid (DNA). Se is a synergistic antioxidant with vitamin E. Its activity appears to be closely related to the anti-oxidative properties of -tocopherol (vitamin E) and coenzyme Q (ubiquinone). It enhances the overall activity of the - ketoglutarate oxidase system, probably by affecting the decarboxylation reaction. The more protein you eat the more pyridoxine your body requires. Proteins especially vitamin E which contains organic selenium is a very powerful anti-oxidant and very effective in the fight against cancer by eliminating the formation of oxidants or free radicals in the body. Vitamin B12, like the other B complex vitamins, is important for metabolism. It also helps form red blood cells and maintains the central nervous system. Vitamin C, also called ascorbic acid, is an antioxidant that promotes healthy teeth and gums. It helps the body absorb iron and maintain healthy tissue. It also promotes wound healing. Vitamin D is also known as the "sunshine vitamin," since it is made by the body after being in the sun. It is very hard to get enough vitamin D from food sources alone. Vitamin D helps the body absorb calcium. Vitamin E as earlier stated, is an antioxidant also known as tocopherol (Tocopherols (TCP) these are a class of organic chemical compounds more precisely, various methylated phenols), many of which have vitamin E activity. Tocotrienols, which are related compounds, also have vitamin E activity. All of these various derivatives with vitamin activity may correctly be referred to as "vitamin E" including selenium). It helps the body form red blood cells and use vitamin K. Vitamin K is not listed among the essential vitamins, but without it blood would not stick together (coagulate). Some studies suggest that it is important for bones' health. Biotin is essential for the metabolism of proteins and carbohydrates, and in the production of hormones and cholesterol. Niacin is a B vitamin that helps maintain healthy skin and nerves.

It also has cholesterol-lowering effects at higher doses which is useful in the treatment and prevention of blood pressure and or diabetes. Folate works with vitamin B12 to help form red blood cells. It is needed for the production of deoxyribonucleic acid (DNA), which controls tissue's growth and cells growth (differentiation, multiplication and elongation) and functions. That is why pregnant women should be sure to get enough folate acid. Low levels of folate are linked to birth defects such as spina bifida (Spina bifida is a birth defect where there is incomplete closing of the backbone and membranes around the spinal cord). Many foods are now fortified with folic acid. Riboflavin (vitamin B2) works with the other B vitamins. It is important for body growth and the production of red blood cells. Thiamine (vitamin B1) helps the body cells change carbohydrates into energy. Getting enough carbohydrates is very important during pregnancy and breastfeeding. It is also essential for hearts to function optimally and healthy nerve cells.

Crude Proteins from the table has an average value of 10.30 percent and composite value of 10.98 percent. It content varies from plant to plants as shown in the above table. Proteins are large, complex molecules that play many critical roles in the body. They do most of the work in cells and are required for the structure, function, and regulation of the body's tissues and organs. Proteins are made up of hundreds or thousands of smaller 
units called amino acids, which are attached to one another in long chains. There are 20 different types of amino acids that can be combined to make a protein. Proteins can be described according to their large range of functions in the body. Proteins Functions as Antibody (Immunoglobulin (IG)): Antibodies bind to specific foreign particles, such as viruses and bacteria, to help protect the body from it. Secondly, if plays the roles of an Enzyme (Phenylalanine hydroxylase); Enzymes carry out almost all of the thousands of chemical reactions that take place in cells. They also assist with the formation of new molecules by reading the genetic information stored in DNA. Proteins also functions as Messengers (Growth hormone): Messenger proteins, such as some types of hormones, transmit signals to coordinate biological processes between different cells, tissues, and organs. Proteins also provide Structural component (Actin): These proteins provide structure and support for cells. On a larger scale, they also allow the body to move in addition to the above roles, proteins serves as media of Transport/storage (Ferritin): These proteins bind and carry atoms and small molecules within cells and throughout the body.

Water/moisture from the table above has an average content value of 1321 percent and composite content value of 19.78 percent. Water is one of the very many vital needs of human beings. A healthy sedentary adult living in a temperate climate should drink at least 1.5 litres of water per day. This level of water intake balances water loss and helps keeping the body properly hydrated. The water you consume through food and drinks follows a very precise route to arrive in your cells, of which it is a vital constituent. After passing through the stomach, water enters the small intestine, where it is largely absorbed in the first sections, the duodenum and jejunum. The rest passes into the colon. It crosses the intestinal mucous membrane into the bloodstream, then into the interstitial tissues that make up the framework of every organ, to arrive in the cells. Blood brings nutritional elements to cells (minerals, vitamins, protein components, lipids and carbohydrates). Waste products are then removes through urines. Water plays also an essential function in helping the regulation of temperature. Secondly, it is important in Chemical and metabolic reactions in the body it does this by enabling hydrolysis reactions. Water participates in the biochemical breakdown of what we eat (proteins, lipids and carbohydrates). It also serves as a medium for Transportation of nutrients and the removal of waste products from the body. Water as a main constituent of blood contributes to the transport of nutrients to the cells. In deed the nutrients are transported by the blood. Water, as a carrier, also helps removing waste products through urines. It also helps in the Body temperature regulation. Water has a large heat capacity which helps limit changes in body temperature in a warm or a cold environment. Water enables the body to release heat when ambient temperature is higher than body temperature we begin to sweat, and the evaporation of water from the skin surface cools the body very efficiently. Water is the very central or heart of life. Drinking water every day (approximately 1.5 litres), and at regular intervals, 8 times a day (before, during and in-between meals), without waiting until you're thirsty, is important as part of a healthy lifestyle

Oils or Lipids from the table of results above, oils has an average content value of 2.36 percent and composite content value of 15.72 percent. Lipids/oil also known as fats play many important roles in human body ranging from providing energy to hormones production. You wouldn't be able to digest and absorb food properly without lipids. Of course, eating more fat than you need can lead to weight gain, but in proper amounts lipids are a healthy part of your diet. Lipids are fats. In the body they take the form of phospholipids, cholesterol and fatty acids. Although fats play a role in obesity and disease, your body needs a certain amount of fat to function optimally. Fat also known as essential body fat, Men need at least 3 percent body fat and women need at least 12 percent body fat to ensure normal functioning. You get triglycerides and phospholipids from your diet, and you get cholesterol from your diet and your body also produces it naturally. The role that lipids play depends on the type of lipid. Triglycerides are also called blood and body fats. As body fat, triglycerides play a role in energy storage. They also provide a layer of insulation under the skin and protective cushioning around the organs. Your body also uses triglycerides to make the myelin sheaths that surround nerve cells. Myelin sheaths act as insulation and help the nerve signal travel faster along the length of the nerve. Triglycerides are solid at body temperature and are classified as saturated fats. If you have too much triglyceride in your blood, it can clot on the blood vessel walls and cause heart disease Cholesterol.

There are two main types of cholesterol, low-density lipoproteins and high-density lipoproteins deliver cholesterol through your bloodstream to serve its bodily functions. When you have excess Low Density Lipoproteins in your bloodstream, cholesterol gets deposited in your arteries. Cholesterol build up can block arteries and cause heart attacks. High Density Lipoproteins transports excess cholesterol from your cells and tissues to your liver, which uses cholesterol to produce bile. According to the National Cholesterol Education Program, desirable cholesterol numbers for adults range from 200 milligrams per decilitre for total cholesterol, less than 100 milligrams per decilitre for LDL and greater than 40 milligrams per decilitre for High Density Lipoproteins. Because High Density Lipoproteins protects against heart disease, higher levels, such as 60 milligrams per decilitre, offer greater protection. Phospholipids are chains of fatty acids.

Fibre from the above table has an average content value of 2.36 percent and composite content value of 7.27 percent. Fibre is made up of the indigestible parts or compounds of plants, which pass relatively unchanged through our stomach and intestines. The main role of fibre is to keep the digestive system healthy. Other terms for dietary fibre include 'bulk' and 'roughage', which can be misleading since some forms of fibre 
are water-soluble and aren't bulky or rough at all. An inverse association has been found between fibre intake and heart attack, and research shows that those eating a high-fibre diet have a 40 percent lower risk of heart disease.1 Stroke: Researchers have found that for every seven-grams more fibre you consume on a daily basis, your stroke risk is decreased by 7 percent. 2 Weight loss and management: Fibre supplements have been shown to enhance weight loss among obese people, 3 likely because fibre increases feelings of fullness. Children aged between four and eight should consume $18 \mathrm{~g}$ of fibre each day. Girls aged 9 to 13, and 14 to 18 years, need $20 \mathrm{~g}$ and $22 \mathrm{~g}$ per day respectively. Boys aged 9 to 13 , and 14 to 18 years, need $24 \mathrm{~g}$ and $28 \mathrm{~g}$ per day respectively. The digestive system slows down with age, so a high-fibre diet becomes even more important. There is good evidence that soluble fibre reduces blood cholesterol levels. When blood cholesterol levels are high, fatty streaks and plaques are deposited along the walls of arteries. Fibrous foods are often bulky and, therefore, filling. Soluble fibre forms a gel that slows down the emptying of the stomach and the transit time of food through the digestive system. This extends the time a person feels satisfied or 'full'. It also delays the absorption of sugars from the intestines. This helps to maintain lower blood sugar levels and prevent a rapid rise in blood insulin levels, which has been linked with obesity and an increased risk of diabetes. Fibre and diabetes .For people with diabetes, eating a diet high in fibre slows glucose absorption from the small intestine into the blood. This reduces the possibility of a surge of insulin, the hormone produced by the pancreas to stabilise blood glucose levels.

Ash from Table 2 shows that it has an average content value of 10.33 percent and composite content value of 7.64 percent. The Ash is the inorganic residue remaining after the water and organic matter have been removed by heating in the presence of oxidizing agents, which provides a measure of the total amount of minerals within a food. Ash content is a measure of the total amount of minerals present within a food, whereas the mineral content is a measure of the amount of specific inorganic components present within a food, such as $\mathrm{Ca}, \mathrm{Na}, \mathrm{K}$ and $\mathrm{Cl}$. High mineral contents are sometimes used to retard the growth of certain microorganisms. Some minerals are essential to a healthy $\operatorname{diet}$ (e.g., calcium, phosphorous, potassium and sodium) whereas others can be toxic (e.g., lead, mercury, cadmium and aluminium) Processing. It is often important to know the mineral content of foods during processing because this affects the physicochemical properties of foods.

\section{Conclusion}

The result above shows that both the seven plants contain very essentials minerals elements and nutritional compositions required in human body for its build up, maintenances and replenishing. Both mineral elements present in the plants are in optimum amount either as trace or major elements. The plants also contain phytochemicals required for the treatment of diseases.

\section{References}

1. American Stroke Association (2017) What is stroke, American Stroke Association.

2. Nwankwo, Chibuzo S, Ebenezer, Ike A, Ahamefula I, et al. (2014) The nutritional and anti-nutritional values of two culinary herbs-uziza leaf (Piper guineense) and scent leaf (Ocimum gratissium) popularly used in Nigeria, International Journal of Scientific \& Engineering Research $5(12)$.

3. Heart Diseases and Stroke Prevention (2017) Know The Facts About Stroke, Centres for Disease Control and Prevention's Division for Heart Disease and Stroke Prevention.

4. Kizhakkayil J, Sasikumar B (2012) Characterization of ginger (Zingiber officinale Rosc.) germplasm based on volatile and non-volatile components, African Journal of Biotechnology 11(4): 777-786.

5. Wadood A, Ghufran M, Jamal SB, Naeem M, Khan A, et al. (2013) Phytochemical Analysis of Medicinal Plants Occurring in Local Area of Mardan, Biochemistry \& Analytical Biochemistry, Abdul Wali Khan University Mardan, Mardan, Pakistan.

6. Peter Crosta (2015) Cancer: Facts, Causes, Symptoms and Research, Medical News Today knowledge center home» cancer» facts, causes and research, Written by Peter Crosta.

7. Bhaumik A, Swapna M, Sucharitha M, Devika K, Ashwini Kumari N ( 2015) The Bioactive Compounds Obtained From The Papaya (Carica Papaya) Act As Potential Anticancer Agents Against The Human Prostate Cancer Cell Line Du-145, International Journal of Pharmacy \& Bio-Sciences, IJPBS 2(1): 1-5.

8. Suhas JV, Taslim TK, Vijay RR, Hitendra SJ (2014) Biochemical constituents in leaf of Carica papaya-ethnomedicinal plant of Kachchh region, International Letters of Natural Sciences 12:16-20.

9. Hossain MA, Salim AL-Raqmi KA, AL-Mijizy ZH, Mohammed Weli A, AlRiyami Q, et al. (2013) Study of total phenol, flavonoids contents and phytochemical screening of various leaves crude extracts of locally grown Thymus vulgaris, Asian Pac J Trop Biomed 3(9): 705-710.

10. Elgadir MA, Mohamed S, Adam A (2014) Carica Papaya As A Source Of Natural Medicine And Its Utilization In Selected Pharmacetical Applications, International Journal of Pharmacy and Pharmaceutical Sciences 6(1): 868-871.

11. Kambai C, Popoola V, Ugbe CJ, Janfa N, Ukanyirioha C (2015) Proximate and Mineral Elements Composition of Honey from Selected Hives in Jos Metropolis, Nigeria, IOSR Journal of Environmental Science, Toxicology and Food Technology (IOSR-JESTFT) 9(9): 94-98.

12. Desai AG, Qazi NG, Ganju RK, Mahmoud El-Tamer, Singh J, et al. (2008) Medicinal Plants and Cancer Chemoprevention, US National Library of Medicine National Institutes of Health Advanced Journal list 9(7): 581-591.

13. I.N.D.S. (2013) (Irish Nutritional and Dietetic Institute).

14. (2017) American Stroke Association (A.S.A) Together to end stroke, Stroke Association.org/Warning Signs.

15. (2010) American Cancer Society A.C.S,/Comprehensive Blood and Cancer Centre (C.B.C.C) What Is Cancer? Cancer Patient Aid Association, Total Management of Cancer. Distributed By: Indian Cancer Initiative.

16. Nath R, Dutta M (2016) Phytochemical and Proximate Analysis of Papaya (Carica papaya) Leaves, Scholars Journal of Agriculture and Veterinary Sciences 3(2): 85-87. 
17. Gomes J, Wachsman AM, Corrigan ML ( 2013) Types of strokes, Handbook of Clinical Nutrition and Stroke, Nutrition and Health, Springer Science and Business Media, New York.

18. White B, Keck MD (2007) Ginger: An Overview, Complementary and alternative medicine School of Medicine, University of Southern California, Los Angeles, California.

19. Samir M, Amrit PS (2003) Medicinal properties of ginger (Zingiber Officianales ROSC.), Natural Products Radiance 2(6): 296-301.

20. Chua LS, Adnan NA (2014) Biochemical and nutritional components of selected honey samples, US National Library of Medicine National Institutes of Health, Acta Sci Pol Technol Aliment 13(2): 169-179.

21. Oche O, Rosemary A, John O, Chidi E, Rebecca SM et al. (2017) Chemical Constituents and Nutrient Composition of Carica papaya and Vernonia amygdalina Leaf Extracts, Journal of Complementary and Alternative Medical Research 2(1): 1-8.

22. Jagadeesh JS, Shalini N (2014) An Overview of Carica papaya and its Medicinal Uses, Research Journal of Pharmaceutical, Biological and Chemical Sciences 5(2): 641-649.

23. Idris S, Iyaka YA, Ndamitso MM, Paiko YB (2011) Nutritional Composition of the Leaves and Stems of Ocimum Gratissimum, Journal of Emerging Trends in Engineering and Applied Sciences 2(5): 801805.

24. Akhtara N, Ihsan-ul-Haqb, Mirzaa B (2015) Phytochemical analysis and comprehensive evaluation of antimicrobial and antioxidant properties of 61 medicinal plant species, Arabian Journal of Chemistry.

25. Pascaline J, Charles M, Lukhoba C, George O (2011) Phytochemical constituents of some medicinal plants used by the Nandis of South Nandi district, Kenya, Journal of Animal \& Plant Sciences 9(3): 12011210.

26. Eyong EU, Agiang MA, Atangwho IJ, Iwara IA, Odey MO, et al. (2011) Phytochemicals and micronutrients composition of rootand stem bark extracts of Vernonia amygdalina Del, Journal of Medicine and Medical Science 2(6): 900-903.

27. I.C.S.S.Q. (2013) Irish Cancer Society smokers quit line.

28. Uyoh EA, Chukwurah PN, David IA, Bassey AC (2013) Evaluation of Antioxidant Capacity of Two Ocimum Species Consumed Locally as Spices in Nigeria as a Justification for Increased Domestication, American Journal of Plant Sciences 4(2): 221-229.

29. Ekhaise FO, Soroh AE, Falodun A (2010) Antibacterial Properties And Preliminary Phytochemical Analysis Of Methanolic Extract Of Ocimum Gratissium (Scent Leaves) Bayero Journal of Pure and Applied Sciences 3(2): 81-83.

30. Nwachukwu CU, Umeh CN, Magnus CN, Kalu IG (2010) Identification and Traditional Uses Of Some Common Medicinal Plants In Ezinihitte Mbaise L.G.A., Of Imo State, Nigeria.

31. Ayoola PB, Adeyeye A (2010) Phytochemical And Nutrient Evaluation Of Carica Papaya (Pawpaw) Leaves, IJRRAS 5(3): 325-328.

32. Saran PL, Ravish C (2013) Drug bioavailability and traditional medicaments of commercially available papaya: African Journal of Agricultural Research 8(25): 3216-3223.

33. Gunde MC, Amnerkar ND (2016) Nutritional, medicinal and pharmacological properties of papaya (Carica papaya linn.): A review, Journal of Innovations in Pharmaceuticals and Biological Sciences 3(1): 162-169.

34. Akhila S, Vijayalakshmi NG (2015) Phytochemical Studies On Carica Papaya Leaf Juice, International Journal of Pharmaceutical Sciences and Research 6(2): 2320-5148.

35. Kemper KJ, M D, M PH (1999) Ginger (Zingiber officinale), The Longwood Herbal Task Force and The Centre for Holistic Pediatric Education and Research.

36. Aravind G, Bhowmik D, Duraivel S, Harish G (2013) Traditional and Medicinal Uses of Carica papaya, Journal of Medicinal Plants Studies 1(1): 7-15.

37. Sasidharan S, Chen Y, Saravanan D, Sundram KM, Yoga Latha L (2010) Extraction, Isolation and Characterization of Bioactive Compounds from Plants' Extracts, African Journals of Traditional Complement and Alternative Medicine 8(1): 1-10.

38. Tiwari P, Kumar B, Kaur M, Kaur G, Kaur H (2011) Phytochemical screening and Extraction: A Review, Internationale Pharmaceutica sciencia $1(1)$.

\section{Your next submission with Juniper Publishers will reach you the below assets}

- Quality Editorial service

- Swift Peer Review

- Reprints availability

- E-prints Service

- Manuscript Podcast for convenient understanding

- Global attainment for your research

- Manuscript accessibility in different formats

( Pdf, E-pub, Full Text, Audio)

- Unceasing customer service

Track the below URL for one-step submission https://juniperpublishers.com/online-submission.php 